Case Report

\title{
An Atypical Porencephalic Cyst Manifesting as a Simple Partial Seizure: A Case Report and Literature Review
}

\author{
Abdulaziz Ibrahim Al Thafar, ${ }^{1}$ Abdullatif Sami Al Rashed, ${ }^{1}$ \\ Bayan Abdullah Al Matar, ${ }^{1}$ Abdulaziz Mohammad Al-Sharydah, ${ }^{2}$ \\ Abdulrahman Hamad Al-Abdulwahhab, ${ }^{2}$ and Sari Saleh Al-Suhibani ${ }^{2}$ \\ ${ }^{1}$ College of Medicine, King Faisal University, Al-Ahsa City, Saudi Arabia \\ ${ }^{2}$ Radiology Department, King Fahd Hospital of the University, Imam Abdulrahman Bin Faisal University (University of Dammam), \\ Dammam, Eastern Province, Saudi Arabia
}

Correspondence should be addressed to Abdulaziz Mohammad Al-Sharydah; amsharydah@uod.edu.sa

Received 9 June 2017; Revised 2 August 2017; Accepted 6 August 2017; Published 5 September 2017

Academic Editor: Pablo Mir

Copyright (c) 2017 Abdulaziz Ibrahim Al Thafar et al. This is an open access article distributed under the Creative Commons Attribution License, which permits unrestricted use, distribution, and reproduction in any medium, provided the original work is properly cited.

\begin{abstract}
Background. Porencephaly is an extremely rare neurological disease characterized by the presence of solitary or multiple degenerative cerebrospinal fluid (CSF) cavities within the brain parenchyma. Case Report. We describe a case involving a 23-yearold male who presented with involuntary movements of the left upper limb of 6 months' duration. A diagnosis of porencephaly was confirmed by magnetic resonance imaging (MRI). Conclusion. The rarity of occurrence and atypical presentation of such a lesion present a challenge to clinicians. Little is known about the pathogenesis and appropriate management of porencephaly. Further studies of the implications of porencephaly for neurodevelopment and behavior are needed.
\end{abstract}

\section{Introduction}

Porencephaly is an extremely rare neurological disease characterized by the presence of solitary or multiple degenerative cerebrospinal fluid (CSF) cavities within the brain matter [1]. Two types of porencephaly have been described: congenital porencephaly and acquired porencephaly [2]. Acquired porencephaly occurs because of infarction, trauma, hemorrhage, infection of the brain parenchyma, and other idiopathic causes [3]. These cavities or cysts may be mild enough to remain unnoticed or severe enough to cause physical and mental disorders. Unfortunately, no populationbased studies of the prevalence of porencephaly have been conducted in Asian countries to date. Furthermore, the overall prevalence of this condition has not yet been explored [4]. A wide spectrum of porencephaly-associated clinical presentations have been reported in the literature [5-8]. To our knowledge, this is the first case of a simple partial seizure caused by an acquired porencephalic cyst, which initially presented with involuntary movements of the left upper limb.

\section{Case Presentation}

A 23-year-old Saudi male presented to the neurology clinic complaining of involuntary left upper limb movements of 6 months' duration. The movements lasted for few seconds and stopped when the arm was held by the other hand. The movements were described as supination and pronation and occurred only when the patient was experiencing stressful situations or getting insufficient sleep. No other factors appeared to induce the attack, which was limited to the left $\mathrm{arm}$. There was no change in the level of consciousness during or before the attacks and there were no other associated symptoms.

The patient's medical history revealed tonic-clonic seizures at 9 years of age, which subsided by the age of 14 years. The seizures occurred during sleep, and there were approximately 6-8 episodes over those 5 years. The patient had received carbamazepine $200 \mathrm{mg}$ per day and had discontinued the medication when the attacks subsided. He had no other significant medical history. The patient's birth 
TABLE 1: Summary of previously reported cases of acquired porencephaly.

\begin{tabular}{|c|c|c|c|c|c|}
\hline & Author [reference] & Age/sex & Presentation & Lesion location & Treatment \\
\hline (1) & Noyan et al. (2016) [9] & 43/female & $\begin{array}{l}\text { First psychotic } \\
\text { episode }\end{array}$ & $\begin{array}{l}\text { Right medial frontal } \\
\text { lobe }\end{array}$ & Antipsychotics \\
\hline (2) & $\begin{array}{l}\text { Hussain et al. (2015) } \\
{[10]}\end{array}$ & 26/female & $\begin{array}{c}\text { First psychotic } \\
\text { episode }\end{array}$ & $\begin{array}{l}\text { Left side of frontal } \\
\text { lobe }\end{array}$ & Antipsychotics \\
\hline (3) & $\begin{array}{c}\text { Sarmast et al. (2012) } \\
{[11]}\end{array}$ & $12 /$ male & $\begin{array}{l}\text { Posttraumatic } \\
\text { diplopia }\end{array}$ & $\begin{array}{l}\text { Left parietooccipital } \\
\text { region }\end{array}$ & Cystoperitoneal shunt \\
\hline (4) & $\begin{array}{c}\text { Douzenis et al. (2010) } \\
{[7]}\end{array}$ & $25 /$ female & $\begin{array}{c}\text { First psychotic } \\
\text { episode }\end{array}$ & Frontotemporal lobes & Antipsychotics \\
\hline (5) & $\begin{array}{l}\text { Ryzenman et al. } \\
\quad(2007)[8]\end{array}$ & 65/female & $\begin{array}{c}\text { Congenital } \\
\text { hemiplegia, left-sided } \\
\text { CSF otorrhea, and } \\
\text { hearing loss }\end{array}$ & $\begin{array}{l}\text { Left cerebral } \\
\text { hemisphere. }\end{array}$ & $\begin{array}{l}\text { Transmastoid } \\
\text { approach }\end{array}$ \\
\hline (6) & $\begin{array}{l}\text { Bhagyabati Devi et al. } \\
(2002)[6]\end{array}$ & $15 /$ male & $\begin{array}{c}\text { Various seizure } \\
\text { patterns }\end{array}$ & $\begin{array}{l}\text { Left cerebral } \\
\text { hemisphere }\end{array}$ & Anticonvulsants \\
\hline (7) & Nakao et al. (1991) [12] & $33 /$ male & $\begin{array}{c}\text { Posttraumatic } \\
\text { headache }\end{array}$ & Left frontal lobe & $\begin{array}{c}\text { Resection and } \\
\text { corticotomy }\end{array}$ \\
\hline (8) & Our case & $23 /$ male & Simple partial seizure & Right frontal lobe & Anticonvulsants \\
\hline
\end{tabular}

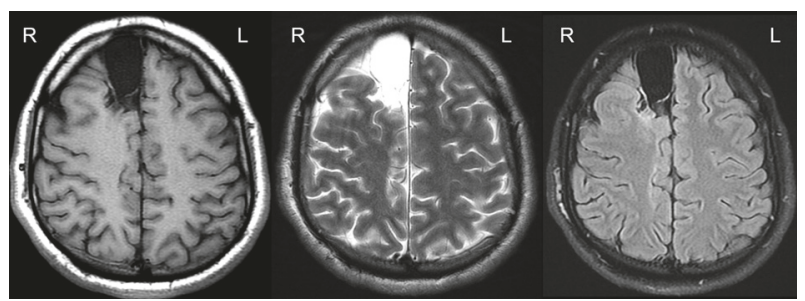

FIGURE 1: Transaxial multisequential magnetic resonance imaging of the brain in the form of a T1 weighted image (WI), T2 WI, and fluid-attenuated inversion recovery (FLAIR) WI, showing an extraaxial, well-defined elliptical lesion located in the right frontal region. The lesion follows the signal intensity of the CSF in all sequences.

history revealed that he was delivered at term by cesarean section, and he was placed in an incubator for 17 days after birth for unknown reasons. No further details were provided regarding his birth history. His surgical history was significant in terms of open reduction and internal fixation of a pathological fracture of the tibia and fibula after a minor sports injury; a nonossifying fibroma was the underlying cause of the pathological fracture. His family history was noncontributory. His general and systemic physical examinations were normal.

The patient's neurological assessment was significant only for hyperreflexia of the left upper limb $(+3$ for left brachioradialis, biceps, and triceps reflexes). The results of his motor, sensory, and cerebellar examinations were normal. The Babinski sign was negative. No abnormalities were found by hematological and biochemistry blood tests (Table 1).

2.1. EEG and Imaging. An EEG recording showed background activity of a well-regulated alpha rhythm, at a frequency of $9 \mathrm{~Hz}$, with maximum amplitude of $70 \mathrm{mcv}$ (referential). Photic stimulation induced a good driving response.

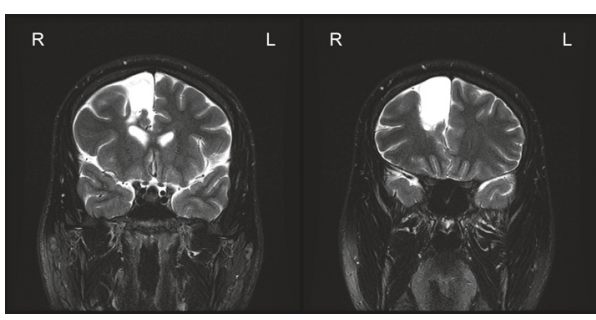

FIGURE 2: A coronal T2 fat-saturated image demonstrates extraaxial T2 signal hyperintensity of the right frontal region, which communicated with the subarachnoid space (anterior interhemispheric fissure) but had no communication with the ventricular system.

Hyperventilation added no further information. Interictal EEG was normal. These findings were consistent with a normal EEG.

Brain MRI with contrast showed corticosubcortical cystic encephalomalacic changes, centered on the right superior frontal gyrus and contacting the right lateral ventricle frontal horn (Figures 1 and 2). These changes included a dominant large unilocular cystic component, measuring around $4 \times 3$ $\times 2.3 \mathrm{~cm}$, which followed the CSF signal on all sequences and lacked overt hemosiderin staining. Thinning of the overlying cortical mantle was present, with mild scalloping of the adjacent calvarial inner table. The dominant cyst was surrounded by smaller cystic changes (Figure 3 ).

These findings were suggestive of a remote insult, probably from a posttraumatic or perinatal ischemic injury, and were consistent with a porencephalic cyst.

2.2. Final Diagnosis and Treatment Plan. The final diagnosis was a simple partial motor seizure caused by acquired porencephaly. Lifestyle modifications and levetiracetam $1000 \mathrm{mg}$ twice daily were prescribed. A follow-up consultation was scheduled for 1 month later. The patient changed his lifestyle 


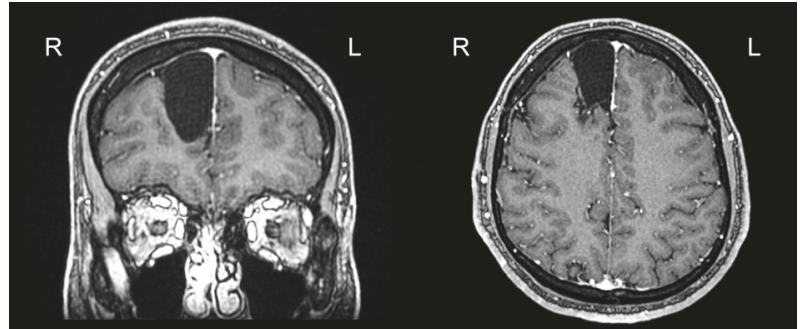

FIGURE 3: Three-dimensional fast spoiled gradient-echo (3D FSPGR) postcontrast axial and coronal images, showing no definitive enhancement of the right frontal lesion.

by avoiding major stressors and ensuring that he obtained sufficient sleep. No additional seizures were experienced while he was on the above treatment plan.

\section{Discussion}

3.1. Pathogenesis and Clinical Presentation. Acquired porencephaly can occur as a result of prenatal or postnatal factors, such as ischemia, traumatic brain injury, or hemorrhage. Hypoperfusion leads to focal encephalomalacia, focal necrosis of both the gray matter and white matter, and eventually cystic degeneration. The pathogenesis of the symptoms is not well understood, but many factors can trigger symptoms in patients, including stressful life events [9] and traumatic injuries [11, 12]. Symptoms can also manifest spontaneously, without any known triggers $[7,8,10]$.

Many of the studies linking the onset of epilepsy with emotional events have methodological weaknesses and have failed to assess possible confounding factors prospectively [13]. Evidence has suggested that individuals with epilepsy who report experiencing emotional seizure triggers show attentional bias toward threats. This association is complicated by the fact that stressful experiences are linked to other potential seizure-precipitating factors (such as sleep deprivation). Thus, the probable indirect trigger for our patient's symptoms was a stressful life event (his father's death).

A wide range of symptoms of porencephaly have been reported in the literature. Most of the reported cases presented with their first psychotic episode before the diagnosis of porencephaly $[7,9,10]$. Our patient presented with a simple partial seizure, with no psychotic symptoms. Bhagyabati Devi et al. reported a case of porencephaly and seizures. The patient presented with multiple types of seizures, which was somewhat similar to our findings [6]. Ryzenman et al. reported a case of porencephaly in which the patient presented with spontaneous CSF otorrhea caused by a massive porencephalic cyst [8]. Another case presented with posttraumatic diplopia [11]. These variations in clinical presentation can be explained by differences in the sizes and sites of the lesions among the cases. The existing literature on patients with late presentation of acquired porencephaly is summarized in Table 1.

3.2. Diagnosis and MRI Findings. MRI is the gold standard for a diagnosis of porencephaly. The typical finding is a cystic space in the brain parenchyma which communicates with an enlarged adjacent ventricle [4]. The diagnostic findings in our case were unique. The MR images revealed extra-axial cystic encephalomalacic changes located on the right superior frontal gyrus (Figures 1 and 2) and abutting the right lateral ventricle frontal horn, including a dominant large unilocular cystic component roughly measuring $4 \times 3 \times 2.3 \mathrm{~cm}$ in maximum dimensions. This cyst followed the CSF signal intensity on the sequences without overt hemosiderin staining and caused thinning of the overlying cortical mantle with mild scalloping of the adjacent calvarial inner table (Figure 3 ). The etiology of these findings is likely a posttraumatic vascular insult, given that the patient was maintained in an incubator for 17 days postnatally for unknown reasons. However, the patient and his mother denied any vascular insult during birth. Nonetheless, an incidental note was made of a developmental venous anomaly at the temporal horn gray-white matter transition, which displayed a satisfactory age-expected appearance. The overall cerebral trophicity was satisfactory, and the hippocampi showed an acceptable anatomical configuration, trophicity, and signal intensity. No evidence of acute or subacute ischemia was seen on diffusion-weighted images.

3.3. Differential Diagnosis. The differential diagnosis included the following conditions: neuroglial cyst, arachnoid cyst, schizencephaly, and ependymal cyst. The diagnosis of porencephaly can easily be missed, since other intracranial cysts can mimic this condition. Neuroglial, or glioependymal, cysts are benign epithelial-lined lesions that can occur anywhere in the neuraxis. Neuroglial cysts appear well-demarcated, without surrounding gliosis, and have the same appearance as the CSF in all sequences [4]. An arachnoid cyst is a benign congenital extracerebral mass that contains CSF surrounded by the arachnoid membrane [14]. Arachnoid cysts are extraaxial and displace the brain cortex from the adjacent skull [4]. Schizencephaly is a gray matter-lined cleft that extends from the pial surface to the ventricle [15]. On imaging, schizencephalic lesions are lined with heterotopic gray matter and extend from the ventricle to the brain surface [4]. Ependymal cysts are benign cysts of the lateral ventricle or juxtaventricular area of the temporoparietal region and frontal lobe [4]. Typically, they present intraventricularly with normal neighboring brain tissue [4].

In conclusion, due to its rarity of occurrence and atypical presentation, porencephaly presents a challenge to clinicians. Little is known about the pathogenesis and treatment of this condition. Further studies are required on this and other cephalic cystic disorders. The extra-axial involvement of this lesion might require further classification in the future. Imaging is essential to establish a diagnosis and thus to determine the best treatment option.

\section{Ethical Approval}

As per the "Imam Abdulrahman Bin Faisal University (University of Dammam) Institutional Review Board," case reports do not require ethical approval or patient consent, provided that there was no intervention and that no patient 
identifiers appear in the report. Therefore, neither ethical approval nor patient consent was required for this case report.

\section{Consent}

Written informed consent was obtained from the patient for publication of his clinical details and radiological studies.

\section{Disclosure}

The authors confirm that all authors have seen and agree with the contents of the manuscript.

\section{Conflicts of Interest}

The authors declare that they have no conflicts of interest.

\section{Authors' Contributions}

Abdulaziz Ibrahim Al Thafar, Abdullatif Sami Al Rashed, Bayan Abdullah Al Matar, Abdulaziz Mohammad AlSharydah, and Abdulrahman Hamad Al-Abdulwahhab participated in the preparation of the manuscript and revised the article for intellectual content. Abdullatif Sami Al Rashed and Sari Saleh Al-Suhibani conducted the literature review and reviewed the patient's medical record. All authors read and approved the final manuscript.

\section{Acknowledgments}

The authors thank Haya F. Al-Hmly (Clinical Dietitian at Johns Hopkins Aramco Healthcare, Dhahran, KSA) for her linguistic revision of the manuscript.

\section{References}

[1] D. B. Gould, F. C. Phalan, G. J. Breedveld et al., "Mutations in Col4al cause perinatal cerebral hemorrhage and porencephaly," Science, vol. 308, no. 5725, pp. 1167-1171, 2005.

[2] G. Tonni, B. Ferrari, C. Defelice, and G. Centini, "Neonatal porencephaly in very low birth weight infants: Ultrasound timing of asphyxial injury and neurodevelopmental outcome at two years of age," Journal of Maternal-Fetal and Neonatal Medicine, vol. 18, no. 6, pp. 361-365, 2005.

[3] N. Hino-Fukuyo, N. Togashi, R. Takahashi et al., "Neuroepidemiology of Porencephaly, Schizencephaly, and Hydranencephaly in Miyagi Prefecture, Japan," Pediatric Neurology, vol. 54, pp. 39-42, 2016.

[4] A. G. Osborn and M. T. Preece, "Intracranial cysts: radiologicpathologic correlation and imaging approach," Radiology, vol. 239, no. 3, pp. 650-654, 2006.

[5] S. S. Ho, R. I. Kuzniecky, F. Gilliam, E. Faught, M. Bebin, and R. Morawetz, "Congenital porencephaly: MR features and relationship to hippocampal sclerosis," American Journal of Neuroradiology, vol. 19, no. 1, pp. 135-141, 1998.

[6] S. Bhagyabati Devi, N. Biplab Singh, T. Bhimo Singh, M. Kulachandra Singh, and K. Chourjit Singh, "Unilateral porencephaly," Indian Pediatrics, vol. 39, no. 5, pp. 495-497, 2002.
[7] A. Douzenis, E. N. Rizos, A. Papadopoulou, M. Papathanasiou, and L. Lykouras, "Porencephaly and psychosis: A case report and review of the literature," BMC Psychiatry, vol. 10, article no. 19, 2010.

[8] J. M. Ryzenman, V. S. Rothholtz, and R. J. Wiet, "Porencephalic cyst: A review of the literature and management of a rare cause of cerebrospinal fluid otorrhea," Otology and Neurotology, vol. 28, no. 3, pp. 381-386, 2007.

[9] O. C. Noyan, C. Şalçini, B. S. Talu, and G. Eryilmaz, "Porencephalic cyst and late onset brief psychotic disorder," BMJ Case Reports, vol. 2016, Article ID 215098, 2016.

[10] T. Hussain, J. A. Bhat, S. Shoib, M. Shafat, R. Mushtaq, and A. A. Malla, "Psychosis in a patient with porencephaly-A case report," Journal of Pioneering Medical Sciences, vol. 5, no. 1, 2015.

[11] A. H. Sarmast, H. I. Showkat, S. Farooq Mir, O. Masood, A. R. Kirmani, and A. R. Bhat, "Traumatic porencephaly with strabismus: A case report," Iranian Red Crescent Medical Journal, vol. 14, no. 7, pp. 457-458, 2012.

[12] N. Nakao, Y. Oiwa, and H. Moriwaki, "Unusual posttraumatic porencephaly. Case report," Neurologia Medico-Chirurgica, vol. 31, no. 3, pp. 169-172, 1991.

[13] B. Novakova, P. R. Harris, A. Ponnusamy, and M. Reuber, "The role of stress as a trigger for epileptic seizures: A narrative review of evidence from human and animal studies," Epilepsia, vol. 54, no. 11, pp. 1866-1876, 2013.

[14] V. Kornienko and I. Pronin, "Diagnostic Neuroradiology," American Journal of Neuroradiology, vol. 30, no. 9, pp. E136E136, 2009.

[15] A. Maurine Packard, V. S. Miller, and M. R. Delgado, "Schizencephaly: Correlations of clinical and radiologic features," Neurology, vol. 48, no. 5, pp. 1427-1434, 1997. 


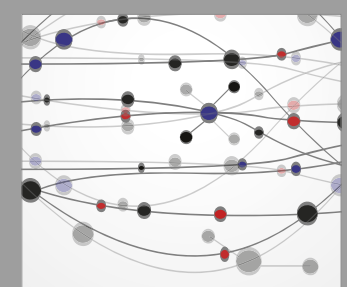

The Scientific World Journal
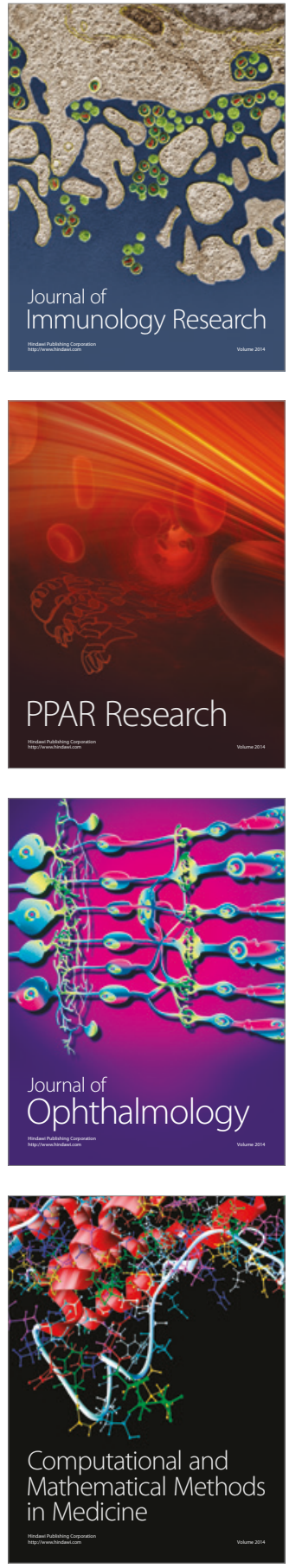

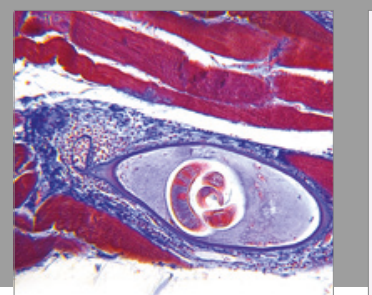

Gastroenterology Research and Practice
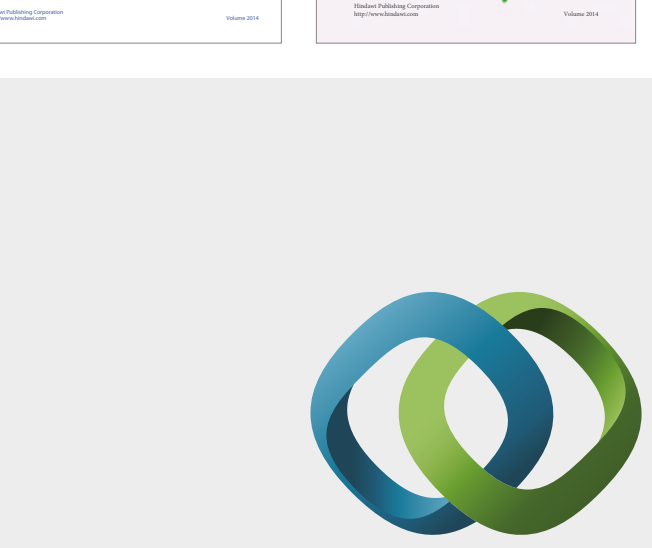

\section{Hindawi}

Submit your manuscripts at

https://www.hindawi.com
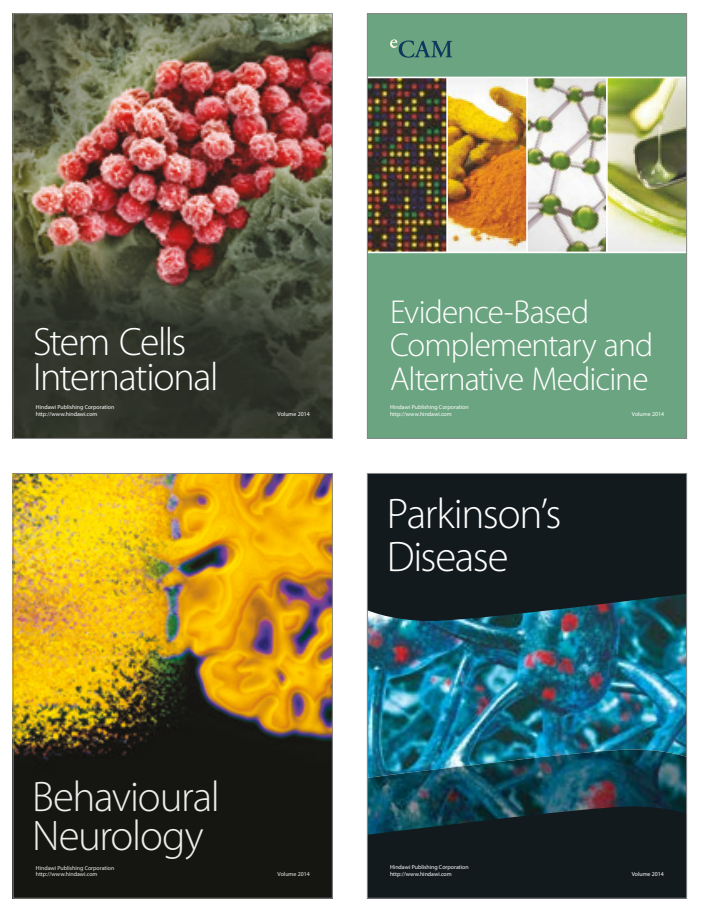
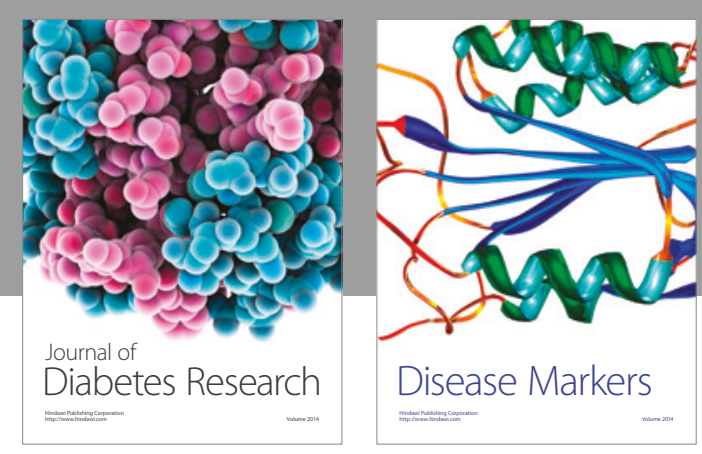

Disease Markers
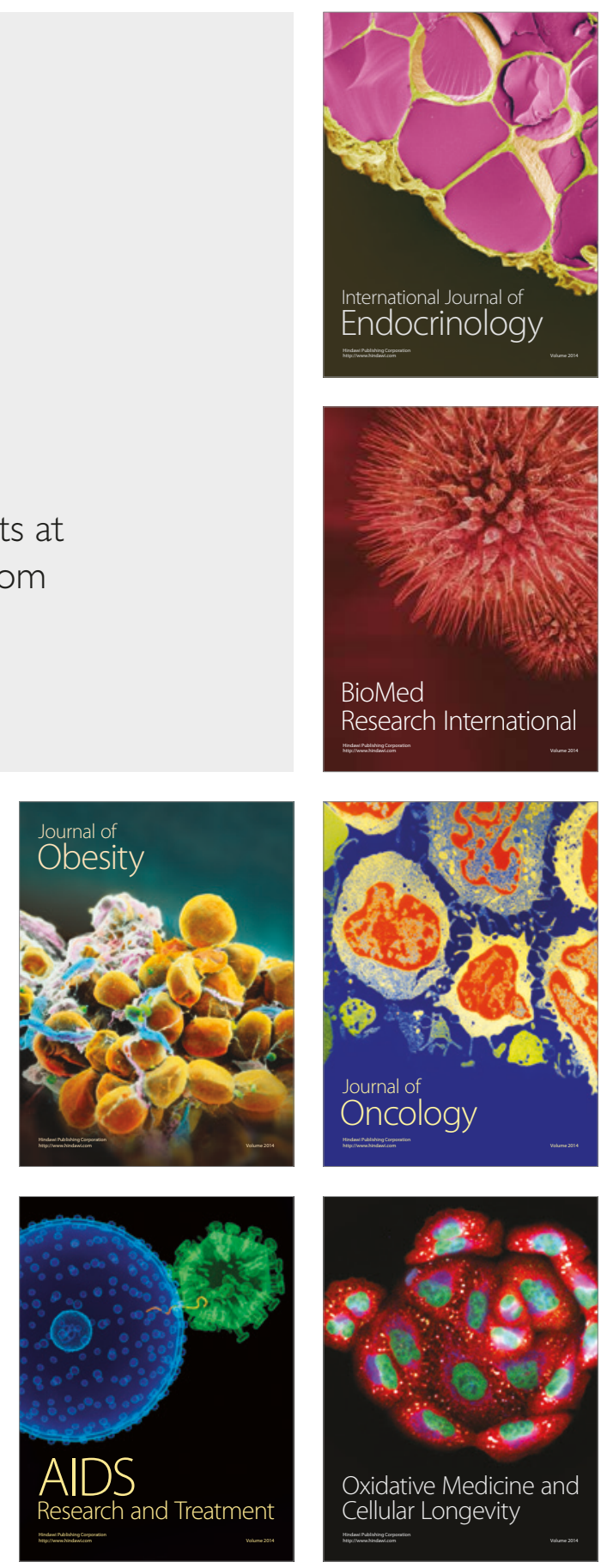